\title{
A ECONOMIA FEMINISTA E A CRÍTICA AO PARADIGMA ECONÔMICO PREDOMINANTE ${ }^{1}$
}

\author{
Marilane Oliveira Teixeira ${ }^{2}$
}

RESUMO: Este artigo trata do surgimento e do desenvolvimento da economia feminista como uma abordagem que se contrapõe à economia predominante, identificando as limitações teóricas e epistemológicas desta corrente para responder aos principais desafios da sociedade. Ao contestar os modelos preconizados pelos neoclássicos, estas economistas se propõem a um novo enfoque que integre a dinâmica da economia e o trabalho de reprodução como partes de um único sistema. Destaca-se, nessa abordagem, aquela que coloca no centro a sustentabilidade da vida humana. Fundamentado em bibliografia especializada o artigo percorre uma vasta literatura produzida nos últimos anos no campo da economia feminista. Essa abordagem ganhou relevância no Brasil somente nas duas últimas décadas e por iniciativa do movimento feminista organizado que, ao elaborar uma crítica às teses neoliberais e apontar as insuficiências da economia tradicional para indicar soluções aos dilemas de uma sociedade cindida por desigualdades seculares, buscou nessa literatura novos aportes teóricos e metodológicos para repensar uma nova economia. Nesse sentido, a economia feminista, com foco na sustentabilidade da vida humana, se constitui em um instrumento valioso de análise que permite uma crítica global ao sistema capitalista e à economia de mercado e, por isso, foi mais rapidamente incorporada pelos movimentos feministas que questionam o liberalismo econômico e a globalização.

PALAVRAS-CHAVE: Economia feminista; reprodução; mercado de trabalho; economia neoclássica; divisão sexual do trabalho.

${ }^{1}$ Este artigo é parte do capítulo I da tese de doutorado "Um olhar da economia feminista para as mulheres: os avanços e as permanências das mulheres no mundo do trabalho entre 2004 e 2013', defendida em 2017 no programa de desenvolvimento econômico e social do Instituto de Economia da UNICAMP.

2 Economista, doutora em desenvolvimento econômico e social pelo IE/UNICAMP, pesquisadora na área de relações de trabalho e gênero. 


\title{
FEMINIST ECONOMICS AND THE CRITIQUE OF THE PREDOMINANT ECONOMIC PARADIGM
}

\begin{abstract}
This article deals with the emergence and development of feminist economics as an approach that opposes the predominant economy, identifying the theoretical and epistemological limitations of this current to respond to the main challenges of society. By challenging the models advocated by the neoclassics, these economists propose a new approach that integrates the dynamics of the economy and the work of reproduction as parts of a single system. In this approach, we highlight the one that places the sustainability of human life at the center. Based on specialized bibliography, the article goes through a vast literature produced in the last years in the field of feminist economics. This approach has gained relevance in Brazil only in the last two decades and at the initiative of the organized feminist movement which, in elaborating a critique of neoliberal theses and pointing out the insufficiencies of the traditional economy to indicate solutions to the dilemmas of a society split by secular inequalities, sought in this literature new theoretical and methodological contributions to rethink a new economy. In this sense, the feminist economy, focusing on the sustainability of human life, constitutes a valuable tool of analysis that allows a global critique of the capitalist system and the market economy and, therefore, was more quickly incorporated by the feminist movements that questioned the economic liberalism and globalization
\end{abstract}

KEYWORDS: feminist economics; reproduction; labor market; neoclassic economy; sexual division of labor.

\section{INTRODUÇÃO}

Este artigo discute a construção de um novo marco conceitual para a disciplina da economia tendo como referência a insatisfação crescente das economistas, pesquisadoras e feministas com a abordagem da economia dominante. Esse novo campo de análise reconhecido como economia feminista irá formular a crítica a economia predominante a partir do reconhecimento de sua estreiteza ao focar em métodos matemáticos fenômenos repletos de conexões e relações de dominação e, com isso, enfraquecendo sua capacidade de explicar os fenômenos do mundo real e em sua visão endocêntrica. Os primeiros ensaios das economistas foram reunidos em um volume de 1993 intitulado: Teoria feminista e economia 
(Ferber; Nelson, 1993). Neste volume, as autoras propõem que a economia passe a ser definida por uma preocupação com a sustentabilidade da vida em todas as esferas em que se realiza e não unicamente pelo mercado.

A publicação de uma série de livros e artigos já entre os anos de 1980 permitiu que a economia feminista se constituísse em um campo teórico organizado no início da década de 1990 ao incorporar trabalhos sobre uma série de assuntos, incluindo tópicos em microeconomia, macroeconomia, história, desenvolvimento econômicos, políticas públicas, filosofia e outras áreas, tais como trabalho, família e cuidados. Desenvolve análises sobre papéis de gênero nos mercados de trabalho e nas famílias. Apresenta estudos sobre a força de trabalho remunerada, a discriminação no mercado de trabalho e as origens da segregação ocupacional. Produz estudos sobre o trabalho não remunerado realizado na esfera familiar com a finalidade de obter medidas quantitativas desse trabalho e aumentar a atenção ao trabalho doméstico e para a formulação de políticas.

A economia feminista irá se colocar como uma contraposição a economia dominante, ao propor que o objeto seja definido antes do método e que o próprio objeto seja redefinido, substituindo a racionalidade econômica pelo que é necessário para a sustentabilidade da vida humana, enfatizando o processo social e as interações sociais e as relações que daí surgem. Ou seja, os resultados materiais são consequência da divisão social entre todos os seus membros e não da maximização dos resultados alcançados pela ação de indivíduos racionais em busca de utilidades.

Neste sentido, a economia feminista procura abarcar todos os campos de estudo da economia e se coloca o desafio de enfrentar algumas questões centrais que representem práticas científicas e que incorporem preocupações como o tema da igualdade salarial no mercado de trabalho, a distribuição do trabalho reprodutivo, as desigualdades e medidas que ajudem a medir o trabalho doméstico não remunerado, as discriminações que as mulheres enfrentam em estruturas ocupacionais e setoriais segmentadas, questões desprezadas pela economia predominante. Esse é um dos propósitos da economia feminista: revelar esses efeitos perversos e essas relações desiguais de poder e desmistificar a neutralidade da economia tradicional. 
Além disso, ela também se propõe a desenvolver novas perspectivas e novas formas de ver o mundo social e econômico que permitam tornar visível o que tradicionalmente a economia predominante não revela.

O artigo está organizado em cinco seções. introdução; a primeira seção trata dos conceitos de trabalho produtivo e reprodutivo como parte de um único sistema; a segunda seção descreve o surgimento e o desenvolvimento da economia feminista como uma abordagem que se contrapõe à economia predominante; a terceira seção identifica as limitações teóricas e epistemológicas da corrente predominante para responder aos principais desafios da sociedade; a quarta seção ao contestar os modelos preconizados pelos neoclássicos, se propõem a um novo enfoque que integre a dinâmica da economia e o trabalho de reprodução com parte de um único sistema. Destaca-se, nessa abordagem, aquela que coloca no centro a sustentabilidade da vida humana; e, por fim as considerações finais.

Nesse sentido, a economia feminista, com foco na sustentabilidade da vida humana, se constitui em um instrumento valioso de análise que permite uma crítica global ao sistema capitalista e à economia de mercado e, por isso, foi mais rapidamente incorporada pelos movimentos feministas que questionam o liberalismo econômico e a globalização.

\section{AS ELABORAÇÕES CONCEITUAIS EM TORNO DO TRABALHO PRODUTIVO E REPRODUTIVO}

Há uma extensa literatura feminista elaborada, especialmente, a partir dos anos de 1960 pelas ciências sociais, e que, somada aos movimentos feministas reivindicatórios, tem dado visibilidade ao tema da divisão sexual do trabalho como aspecto central para a compreensão sobre a construção das relações de desigualdade entre mulheres e homens. No entanto, a construção de uma interpretação que compreende o feminismo como ideologia e prática da luta pela libertação das mulheres, que atribui às relações um conteúdo em que se evidencia a desigualdade nas relações sociais de sexo, compreende a subordinação econômica, cultural, individual de mulheres como categoria social em contraposição aos paradigmas 
construídos que excluem essas contradições, continua sendo um grande desafio para as ciências sociais.

As primeiras manifestações que questionam o não reconhecimento das condições de inserção das mulheres no mundo produtivo se desenvolvem quase em paralelo ao pensamento econômico. Ainda que a crítica metodológica e epistemológica às tradições existentes, como uma importante elaboração teórica e análise empírica, tenha ganhado força a partir dos anos setenta do século XX, já havia desde o século anterior uma presença forte de mulheres pioneiras que ousaram reivindicar direitos iguais, emprego e denunciavam as desigualdades no trabalho e as diferenças salariais entre os sexos (Carrasco, 2006).

A teoria feminista e a crítica às práticas dominantes na economia constituem as grandes inspirações para o desenvolvimento da economia feminista. No entanto, esse campo de análise é muito recente ${ }^{3}$ e vem crescendo muito lentamente no interior da Teoria Econômica. As primeiras discussões públicas organizadas com a introdução do tema no debate econômico surgiram nos Estados Unidos, no final dos anos de 1980 com o surgimento da Associação Internacional para Economia Feminista (IAFFE). ${ }^{4}$

Não há uma definição geral aceita de economia feminista que, em princípio, procura cobrir todos os campos que podem ser estudados em economia, a partir de uma abordagem feminista. Robeyns (2000:3) reconhece a tarefa árdua da economia feminista na condução da pesquisa nos diversos campos da teoria econômica. ${ }^{5}$ Argumenta que ela desenvolveu-se sobre uma crescente insatisfação por parte das feministas

\footnotetext{
${ }^{3}$ Há uma defasagem entre o desenvolvimento da economia feminista e as demais escolas feministas em outras disciplinas. Nos anos de 1970 e 1980 as outras disciplinas já avançavam em seus estudos, enquanto na economia praticamente inexistiam pesquisas nessa direção.

4 Nos Estados Unidos, as primeiras discussões públicas organizadas sobre "economia feminista" ocorreram em encontros da Associação Econômica do Sul e Associação Econômica Americana, em 1989. Isso resultou, em 1992, no surgimento da Associação Internacional para Economia Feminista (IAFFE). A revista Feminist Economics, que já se encontra em sua $24^{a}$ edição em julho de 2018, foi criada em 1993.

${ }^{5}$ Para a autora, deve ser muito mais árduo conduzir pesquisa nas estruturas de preços de títulos e ações do que na economia social e do trabalho (Robeyns, 2000:3).
} 
no que se refere à metodologia, epistemologia e ontologia implícitas na economia neoclássica ${ }^{6}$. Sendo assim, qualquer abordagem sobre a economia feminista deve considerar, necessariamente, a crítica à economia predominante ou neoclássica.

Mesmo considerando que as demais escolas econômicas negligenciaram a perspectiva de gênero em suas teorias, partimos da crítica à escola neoclássica porque é ela que orienta as políticas econômicas predominantes e sustenta todo o ideário neoliberal que se encontra na raiz das desigualdades sociais e econômicas. Seus pressupostos estão orientados por uma nítida divisão social e sexual do trabalho e suas formulações expressam o lugar das mulheres na atividade econômica, como reprodutoras da força de trabalho.

Portanto, o que torna diferente a economia feminista da economia predominante e das demais escolas econômicas é o persistente questionamento da dimensão básica de gênero, seja por meio de fenômenos particulares ou de implicações de gênero a partir de decisões de caráter macroeconômico, dimensão está esquecida ou ignorada pelas demais escolas de pensamento econômico.

Neste sentido, o marco para a construção de uma vasta elaboração teórica e aplicada que posteriormente se denominará economista feminista é a década de 1980. O uso das categorias "gênero" e "patriarcado" conceitos construídos nos anos de 1970 e fundamentais para o feminismo se generaliza entre as economistas feministas. O conceito de "gênero" será particularmente importante para os estudos sobre o trabalho. Entretanto, é nos anos de 1990 que se verifica a consolidação da economia feminista enquanto uma corrente de pensamento.

De acordo com Carrasco (2006), neste processo de construção da economia feminista, dois eixos básicos de pensamento orientaram o desenvolvimento da pesquisa: o eixo que se denomina economia e gênero e o eixo designado economia feminista. Trata-se de linhas de pensamento que se expressam nas elaborações criadas a partir da teoria feminista.

\footnotetext{
${ }^{6}$ Somente a partir da década de 1930 e 1940 a Teoria Marginalista passa a ser denominada economia neoclássica.
} 
Grosso modo, correndo o risco de exagerar nas simplificações, podemos identificar, na teoria feminista, ao menos duas grandes linhas de pensamento que contribuíram para a formulação da economia feminista. A primeira enfatiza a conquista dos direitos e a igualdade entre os sexos, sem alterar o modelo dominante. A segunda perspectiva reconhece a importância da igualdade de direitos e avança em uma perspectiva que propõe a compreensão da problemática, compreendida a partir das próprias mulheres, de suas potencialidades, de sua riqueza, e não daquilo que falta para se igualarem aos homens (Carrasco, 2006).

Para as autoras (Picchio; Carrasco) quando essas duas linhas de pensamento são traduzidas para o campo econômico, o enfoque economia e gênero destaca as desigualdades econômicas entre mulheres e homens, mas dentro dos marcos analíticos já estabelecidos, sem questioná-los. Ao contrário, a economia feminista ressalta a necessidade de superar a estrutura dicotômica, para então construir paradigmas mais apropriados para a análise socioeconômica e a integração das diversas atividades que fazem parte da reprodução social e da sustentabilidade da vida humana (Picchio, 1999; Carrasco, 2001).

Para a economia feminista, a economia monetária depende da economia não monetária por razões óbvias, visto que os salários pagos são insuficientes e as famílias dependem do trabalho realizado no âmbito doméstico e das relações afetivas e emocionais, que não podem ser adquiridas no mercado e são essenciais para o ser humano.

Neste sentido, alguns temas são centrais para a economia feminista, como os programas de ajuste estrutural propostos pelos governos e seus impactos sobre as mulheres; a distribuição dos recursos públicos de forma a favorecer o ingresso das mulheres no mercado de trabalho; a divisão sexual do trabalho; a distribuição na sociedade entre o trabalho remunerado e não remunerado; os sistemas de seguridade social e contribuição previdenciária, entre outros.

Entretanto, dentro dos enfoques que se colocam no âmbito da economia feminista, destaca-se uma linha de estudo, objeto deste trabalho, que adota como ponto de partida a centralidade da vida humana. Este enfoque, conhecido como "economia feminista da ruptura", tem vários 
pontos de congruência com o enfoque das "capacidades", desenvolvido por Amartya Sem (1999), Martha Nussbaum (2000) e o enfoque da Reprodução Social, de Antonella Picchio (1999).

Diferentemente da economia neoclássica, que centra sua análise na utilização eficiente e racional dos recursos, a proposta deste estudo é destacar as elaborações teóricas que reconhecem a importância do trabalho reprodutivo, tornando visíveis as distintas atividades que são realizadas no interior das sociedades. Ao propor novas perspectivas de análise esses estudos possibilitam uma abordagem crítica sobre por que as mulheres se inserem nas ocupações tradicionalmente identificadas com o sexo, por que recebem remuneração inferior à do sexo masculino e são maioria entre as pessoas desempregadas e na informalidade. Ao mesmo tempo que permitem a discussão de novas estatísticas, construir novos indicadores, discutir em outros termos as políticas públicas, modificar a perspectiva de análise, reconhecendo e dando valor ao trabalho não remunerado realizado tradicionalmente pelas mulheres, cujo objetivo direto é o cuidado da vida humana.

O desvendamento do caráter social presente nas desigualdades entre mulheres e homens é uma contribuição dos movimentos feministas que eclodiram na década de 1960, conhecidos como "segunda onda do feminismo". Para caracterizar essa relação, se desenvolveram dois conceitos em paralelo: "gênero" e "relações sociais de sexo"7.

O desenvolvimento do conceito de relações sociais de sexo e do conceito
de gênero constitui-se em um processo importante da elaboração teórica
visando a possibilitar, de forma complexa e integral, uma compreensão
das relaçôes entre mulheres e homens, como categorias sociais.
(Godinho, 2007:41)

7 Segundo Godinho (2007), a elaboração em torno do conceito de 'relações sociais de sexo'
desenvolveu-se mais amplamente na literatura francesa e sua divulgação ocorreu no Brasil
bastante vinculada às discussões sobre o mundo do trabalho e à noção de divisão sexual do
trabalho. A partir dos anos de 1980, com o avanço da difusão da literatura feminista de língua
inglesa, o conceito de 'gênero' se generaliza inclusive entre as francesas. Na sua avaliação,
essa supremacia é resultado da perda de espaço que a temática do trabalho sofreria nos anos
seguintes e o crescimento do feminismo pós-estruturalista. No Brasil o conceito de 'gênero'
chega por meio dos trabalhos de Joan Scott (2007:42).

Temáticas, Campinas, 26, (52): 135-166, ago./dez. 2018 
Para Hirata (2002:275), relação social é um conceito que se relaciona ao de divisão sexual do trabalho. Kergoat (2009:71) a define assim: "As relações sociais de sexo e a divisão sexual do trabalho são expressões indissociáveis que, epistemologicamente, formam um sistema". As expressões são coextensivas, ou seja, há uma sobreposição parcial de uma pela outra.

Neste sentido, o conceito de "relações sociais de sexo" parece mais adequado uma vez que permite articular as relações de exploração com as de opressão e abre novas perspectivas para uma redefinição do conceito de 'trabalho', além de colocar em um mesmo plano as relações de classe e as relações de sexo. O que implica dizer que não é suficiente enfrentar as opressões de gênero se não estiveram articuladas com as dimensões de classe, uma vez que são parte de um único sistema.

\section{A INVISIBILIDADE DAS MULHERES NA FORMAÇÃO DO PENSAMENTO ECONÔMICO}

Nesta seção será abordada a ausência de um enfoque de relações sociais de sexo nos estudos econômicos, a despeito dos esforços de economistas feministas que há vários anos vêm desenvolvendo estudos e pesquisas com o objetivo de enriquecer o pensamento econômico. É a partir de um olhar crítico ao pensamento conservador que domina as ciências econômicas que estão sendo construídas novas metodologias que permitem abordar os processos econômicos considerando os agentes econômicos enquanto mulheres e homens.

O aumento dos estudos feministas nos últimos anos tem representado um grande impacto sobre a pesquisa acadêmica e os estudos que incorporam uma visão de gênero. Tanto na filosofia, quanto na antropologia e nas ciências sociais este processo vem transformando o tipo de pesquisa que está sendo feita. Nas ciências econômicas, os estudos vêm se desenvolvendo também, porém, lentamente. Além disso, os estudos com abordagem feminista são muito recentes no campo econômico.

Como apontaram MacDonald (1984) e McFarland (1976), a conjunção das limitações metodológicas e controles ideológicos presentes 
no conteúdo e natureza da teorização econômica significou que os assuntos econômicos relativos às mulheres só foram abordados fora da disciplina, principalmente por sociólogos que escapam das consequências da hegemonia neoclássica. O reverso dessa situação, denunciado por Louise Vandelac (1986), é que as mulheres economistas são forçadas a adotar o discurso dominante. Ignoradas enquanto sujeito econômico, as mulheres são reprimidas dentro do campo econômico predominante. Isso por sua vez legitima a disciplina e paradoxalmente "contribui para manter a ilusão da neutralidade desse discurso" (Vandelac, 1986:17 APud Pujol, 1998).

Ao analisar a presença das mulheres nos estudos econômicos, MacDonald conclui que falta à economia um campo específico dedicado ao estudo das mulheres (1984:152). Os estudos sobre "a nova economia doméstica”, surgidos na década de 1950, com o objetivo de responder à crescente presença das mulheres no mercado de trabalho, por meio de modelos de utilidade, contribuíram mais para a manutenção e racionalização do status quo patriarcal do que propriamente para um estudo sobre as mulheres. Ao preencher momentaneamente um vazio teórico, suas formulações contribuíram para retardar o desenvolvimento da economia feminista.

No campo das ciências sociais, a ciência econômica é a mais dominada pelos homens e a que apresenta maior resistência em incorporar a questão das mulheres. Trata-se de uma ciência extremamente resistente às mudanças, pouco sensível a questionamentos, muito pouco aberta a questões epistemológicas ou pesquisas interdisciplinares. Embora a análise feminista venha penetrando no campo da economia, esta continua sendo a ciência social menos permeável aos desafios propostos pelo feminismo. Os esforços realizados pelas economistas feministas em tratar do tema das mulheres não se reverteram no sentido de que o gênero como categoria de análise tenha transformado os estudos econômicos e alterado seus pressupostos fundamentais.

Entretanto, a literatura econômica com enfoque feminista ou com uma abordagem de gênero cresceu diante do visível aumento de mulheres no mercado de trabalho e das pressões feministas. Análises sobre o 
trabalho das mulheres no mercado e nas casas estão presentes nos diversos paradigmas neoclássicos, institucionalistas e marxistas. Estas análises, contudo, se mostraram limitadas, uma vez que estão impregnadas de uma concepção que separa o público do privado e não reconhecem as relações de opressão e subordinação presentes na divisão sexual do trabalho.

Uma das primeiras economistas feministas que ousou fazer uma revisão na história do pensamento econômico foi Madden (1972), ao propor uma abordagem que trata o conceito de construção social de gênero e seu vínculo com as análises econômicas.

Para a autora, se os assuntos discutidos em publicações de economia tradicionais são indicadores das preocupações dos economistas com o tema, então tem havido uma evidente falta de interesse profissional pelos problemas das mulheres. Quinze anos mais tarde, Bergmann (1987) percebe uma polarização entre as tentativas das economistas feministas e um componente antifeminista forte da escola neoclássica.

Portanto, uma história do pensamento econômico sobre as mulheres tem que ser acompanhada de comentários escritos por feministas, a partir de referências implícitas e explícitas à discriminação sexual nas discussões de economia ou à discriminação racial e à exploração de classes sociais e aos debates políticos sobre a igualdade de remuneração e legislação (Madden, 1972:21).

Em dois períodos distintos - na década de 1930, com os estudos sobre as diferenças salariais entre mulheres e homens e, posteriormente, com os trabalhos sobre a produção doméstica e o uso do tempo nos anos de 1960 e 1970 - os estudos sobre as desigualdades entre mulheres e homens estiveram centrados nas dinâmicas do mercado ao invés de enfocarem o papel da dimensão de gênero e das desigualdades nas relações de poder. O conceito de construção social de gênero e seu vínculo com a análise econômica ainda não havia surgido.

Foi nas décadas de 1970 e 1980 que cresceu a influência do feminismo sobre as análises econômicas. Suas contribuições têm se dirigido a distintas áreas, incluindo tanto as análises históricas, como as teóricas e as empíricas. No entanto, a economia tradicional, acostumada à sua hegemonia, é reticente em admitir a importância do gênero como 
categoria central de análise, com impacto na construção do conhecimento empírico e teórico (Benería, 2004:24).

Uma parte importante da literatura feminista tem se concentrado na construção social da economia feminista como disciplina. Estas contribuições têm sido realizadas, em geral, desde uma perspectiva feminista e da desconstrução da economia ortodoxa, particularmente sua versão neoclássica. Esses trabalhos introduzem uma crítica aos pressupostos sobre o funcionamento do mercado e a sociedade de mercado. Questionam a concepção acerca da natureza do ser humano baseada na figura do homo economicus, agentes autônomos, racionais, com preferências estáveis e que interagem com o único propósito de trocar; o método de análise restrito quase exclusivamente ao uso de modelos matemáticos e econométricos. A crítica vem acompanhada de um debate sobre a natureza do mercado e a forma como impulsiona ou restringe os objetivos e ações dos indivíduos e das comunidades (Benería, 2004:37).

$\mathrm{O}$ debate tem mostrado que a economia feminista aglutina uma variedade dessas perspectivas. Estas posturas variam desde a aceitação do mercado como fonte de crescimento material e a liberdade individual até outras que criticam sua incapacidade para satisfazer as necessidades de todos os grupos sociais. Uma destas críticas se direcionou aos pressupostos da racionalidade econômica e ao comportamento maximizador dos agentes como sendo a norma que conduz e na qual repousa a economia ortodoxa. O questionamento da economia feminista põe foco na retórica da eficiência.

Para Benería:

Esta mirada crítica al concepto de eficiencia y su importancia fundamental en el análisis económico están basadas en la observación de que: a) el óptimo de Pareto presupone que 'el bienestar económico puede calcularse de acuerdo con un único sistema de medición y b) los temas distributivos no pertenecen al ámbito de la ciencias económicas. (Benería, 2004:37)

Entretanto a participação das mulheres na força de trabalho não passou despercebida por alguns autores de inspiração neoclássica. Foi Temáticas, Campinas, 26, (52): 135-166, ago./dez. 2018 
por meio de Jacob Mincer na década de 1950 e de outros economistas que se começou a explicar o crescimento deste fenômeno em um período em que a renda familiar estava aumentando. Normalmente se supõe, de acordo com a economia neoclássica, uma relação inversa entre oferta de trabalho e renda ${ }^{8}$. Ou seja, por que as mulheres ingressavam massivamente no mercado de trabalho se a renda familiar aumentava? A explicação para este fenômeno está no efeito substituição.

Para esses autores, o aumento dos salários como resultado do crescimento econômico desse período havia criado um incentivo econômico para que as mulheres buscassem um trabalho remunerado. Sustentava-se que o efeito substituição superava o efeito renda, que estimulava as mulheres a permanecerem em casa.

Becker (1987), posteriormente, vai argumentar que um aumento no salário das mulheres aumentava o custo de oportunidade das atividades domésticas, o custo de ter muitos filhos e o custo de ter filhos com um intervalo de tempo distante entre eles. E isto pode ter levado a um aumento da participação feminina.

Na década de 1950 as mulheres começaram a ingressar maciçamente no mercado de trabalho. Betty Friedan (1971), em A Mística Feminina, descreve os dramas que as mulheres donas de casa enfrentavam na sociedade americana. A descrição de Friedan sobre a opressão das mulheres e a frustração das donas de casa contrastava com a descrição feita por meio de modelos de custos de oportunidade, de Mincer, propostos pela análise econômica. O contraste entre os dois enfoques reforçava a necessidade de se buscar respostas à questão das mulheres para além de um modelo

\footnotetext{
${ }^{8} \mathrm{Na}$ teoria neoclássica, a decisão de oferta de trabalho é definida num contexto de maximização de utilidades dos indivíduos, em que os argumentos da função utilidade são quantidades de bens e horas de lazer. A maximização está sujeita a uma restrição orçamentária, que é afetada pela renda não oriunda do trabalho, pelo tempo, pelos preços dos bens e o preço do lazer. O indivíduo participa da força de trabalho sempre que o salário de mercado exceder seu salário de reserva, entendido como sendo o quanto o indivíduo exige de remuneração adicional para abrir mão de uma hora de lazer, quando não está trabalhando. Para os neoclássicos o salário de reserva tem um papel crucial na determinação da entrada ou não no mercado. $\mathrm{O}$ aumento na renda dos outros membros do domićlío e do número de adultos tende a aumentar o salário de reserva da mulher, levando a uma menor possibilidade de sua participação no mercado de trabalho.
} 
rígido de análise estritamente econômica (Benería, 2004:26). Entretanto, os estudos de Mincer e de outros economistas representaram a transição para um maior interesse da análise econômica para com a esfera doméstica.

\section{UMA PERSPECTIVA METODOLÓGICA PARA A ECONOMIA FEMINISTA}

Nos estudos econômicos, metodologia significa os métodos pelos quais economistas decidem o que será conhecimento econômico. A metodologia econômica pode se referir, algumas vezes, ao conjunto de ferramentas e técnicas utilizadas pelos economistas para explorar relações econômicas, tais como seus modelos teóricos e empíricos, avaliação e análises envolvendo múltiplas variáveis. Em outros momentos a metodologia está relacionada a processos epistemológicos, ou seja, aos métodos pelos quais economistas decidem o que será conhecimento econômico, que dependem de autoridade disciplinar e legitimação (Grapard, 1999:545).

Trata-se de métodos inter-relacionados, uma vez que ferramentas e métodos são definidos a partir de posições teóricas e epistemológicas, assim como este posicionamento é determinado, muitas vezes, pelas ferramentas e métodos.

Nem toda a pesquisa econômica que trata de mulheres ou gênero é necessariamente economia feminista. A economia feminista parte de uma crítica à supremacia masculina e de uma convicção de que é possível transformar o discurso econômico; enquanto que os estudos de gênero, na sua maioria, apenas incorporam as mulheres, sem, em geral, realizar a crítica aos fundamentos de tais estudos.

Entre as economistas feministas há uma concordância de que os estudos econômicos, até muito recentemente, negligenciaram a contribuição das mulheres, mas essas economistas reconhecem o papel de gênero em todos os contextos econômicos. Para Grapard, a desatenção histórica impõe, para todas as escolas de pensamento em economia, uma reavaliação de seus fundamentos teóricos e práticos (Grapard, 1999:545).

A simultaneidade de escolas de pensamento ortodoxas ou neoclássicas, ao lado de várias escolas heterodoxas de pensamento, tais 
como a marxista, institucionalista, keynesiana, entre outras, significa que não há um único grupo unificado de hipóteses sobre a natureza do conhecimento, a natureza do mundo real e a natureza humana, entre os economistas.

Sendo assim, a economia feminista se propõe a apresentar uma extensa crítica metodológica sobre o conjunto da disciplina de economia, bem como os desafios específicos em cada escola de pensamento. Os avanços na teoria feminista nestes últimos trinta anos influenciaram significativamente a economia feminista.

Para a maior parte das teóricas, o feminismo não é simplesmente uma perspectiva ou um modo de ver, tampouco uma epistemologia, uma forma de conhecer; é também ontologia, ou seja, uma maneira de estar no mundo.

Dentre as contribuições mais importantes para as questões de metodologia, destaca-se a oriunda da filosofia da ciência, particularmente os trabalhos desenvolvidos por Harding (1986, 1991). A autora mostra que a crítica feminista levanta questões sobre a estrutura social e uso da ciência, assim como sobre as origens, as problemáticas e os significados sociais.

Harding examina três perspectivas teóricas feministas importantes para a economia feminista que vão influenciar o método de análise. Com o desenvolvimento de novas teorias do conhecimento, emergiram principalmente três tendências feministas ou três epistemologias: o empiricismo feminista (feminist empiricism), as teorias do ponto de vista (feminism standpoint) e o feminismo pós-moderno (feminism postmodernism).

$\mathrm{O}$ empiricismo feminista assume uma posição liberal quanto à pesquisa, tentando corrigir preconceitos de gênero na investigação. Recorre aos métodos tradicionais, com predominância dos métodos quantitativos. Fundamenta-se na racionalidade e objetividade da ciência e, dessa forma, tenta debelar todas as formas de manifestação de atitudes sexistas na investigação (Grapard, 1999:547). É uma réplica, como argumenta Harding (1991), aos preconceitos sexistas na investigação tradicional e a uma visão androcêntrica dominante nas ciências sociais. 
O empiricismo feminista desenvolveu-se em consonância com o feminismo liberal e, tal como a teoria liberal feminista, tem como objetivo a identificação e a eliminação de estereótipos, sexismos e discriminações em qualquer processo de investigação. Mas é alvo de crítica ao não questionar as bases da investigação científica, nem desafiar a própria natureza do conhecimento.

Para as teóricas do "ponto de vista" feminista (standpoint), uma renovação na ciência tem inevitavelmente que incluir as experiências específicas das mulheres. Essas experiências potencializarão o desenvolvimento de um conhecimento mais completo, menos distorcido do que o conhecimento predominante construído a partir de uma perspectiva masculina.

Considerando que o ponto de partida e o foco da investigação feminista são as experiências das mulheres, não se deve considerar um "ponto de vista" único e universal, mas que as distintas experiências de vida das mulheres e dos homens estão fortemente associadas com as realidades concretas em que estão inseridos Para essas teóricas, a definição das discussões econômicas consideradas legítimas e vantajosas para serem investigadas, na maior parte das vezes, é reflexo do privilégio social e da posição econômica e política dos homens.

Entre as críticas a essa teoria está a sua tendência para a universalização de conceitos como "mulheres" ou "ponto de vista feminino". É importante reconhecer que as mulheres são diferentes e não podem ser simplesmente categorizadas sem se considerar as relações que, como grupo, estabelecem com outros grupos: raça, faixa etária, classe social etc.

Em termos epistemológicos, pode-se falar de uma pluralidade de "pontos de vista" feministas. As epistemologias identificadas com o Iluminismo, por exemplo, foram colocadas em dúvida por várias feministas associadas a movimentos contra o Iluminismo e por feministas das correntes do pós-modernismo e do pós-estruturalismo.

Essas feministas questionaram e confrontaram as bases teóricas do empiricismo do ponto de vista feminista "standpoint" e desenvolveram novas perspectivas epistemológicas feministas com estreitas relações com o pensamento pós-moderno. 
O feminismo pós-moderno sugere a existência de variados pontos de vista feministas contraditórios e conflituosos. Entre os/as investigadores/ as pós-modernos/as, não se reconhece a existência de um "modo correto" na interpretação dos dados. É da responsabilidade do/a investigador/a explorar as possíveis e diferentes interpretações.

A teoria feminista pós-moderna implica o afastamento de noções unitárias de mulher e de identidade de gênero feminina e a adoção de concepções complexas, plurais, como a de construção de identidade social. O gênero é tão importante quanto é a idade, a etnia e a orientação sexual.

Essas três perspectivas são abordadas pela economia feminista conforme se identifiquem com as suas próprias reflexões. Não há uma teoria ampla que seja capaz de unificar as feministas em torno de uma metodologia, mas aproximações que contribuem para a construção de certos argumentos na economia feminista.

As estruturas teóricas e práticas atuais de investigação econômica são influenciadas por uma prática científica convencional, leia-se machista. O modelo de otimização da economia neoclássica apresenta um agente econômico racional que é separado e independente das relações sociais externas. Esse indivíduo maximizador representa uma posição puramente masculina e modela o comportamento dos demais que não se ajustam à sua imagem.

Na teoria econômica padrão, o homem econômico racional ("homo economicus”), obtém utilidade ou satisfação consumindo bens e serviços. As origens das preferências, ressaltando-se sua função utilitária, não é objeto de análise econômica, e esta utilidade não é aceita como sendo influenciada por outros. Ou seja, gostos e preferências são considerados externos ao modelo, e comparações de utilidade que envolvem duas ou mais pessoas são simplesmente descartadas.

As relações humanas e sociais, sem as quais a sociedade humana não existiria, são colocadas fora da esfera da teoria econômica, o que torna invisível grande parte do trabalho de cuidados, especialmente do trabalho das mulheres. Nelson argumenta que, em nossa cultura, a desvalorização sistemática das mulheres e do feminino está atrás do privilégio do masculino. Ela mostra como nossa cultura associa tributos positivos com 
a masculinidade e valores negativos com a feminilidade e isso revela o dualismo e os preconceitos masculinos dos valores incorporados na teoria neoclássica e em suas práticas (Nelson, 1996:20-38).

Ela enfatiza que o desenvolvimento de uma estrutura teórica mais rica não acontecerá porque as mulheres, por alguma razão, fazem a economia de maneira diversa, mas por incluírem valores e experiências previamente excluídas, fornecendo dados melhores e mais completos para serem trabalhados. E, por essa razão, são capazes de produzir uma ciência econômica mais objetiva (Nelson, 1996: 20-38).

Uma importante análise sobre a retórica da economia foi proposta por McCloskey (1998). Ela argumenta que economistas não praticam o que defendem, ou seja, não aderem aos princípios metodológicos científicos, rigorosos e racionais que normalmente defendem; ao invés disso, utilizam artifícios retóricos e narração de histórias num esforço de persuadir os demais. As economistas feministas têm examinado essas estratégias de narrativa utilizadas nos discursos econômicos a fim de registrar a natureza de gênero das histórias e metáforas. Essa análise permite identificar as dimensões políticas de um discurso que constrói o agente econômico e o domínio da economia de forma masculinizada e ocidentalizada.

Até muito recentemente, as operações de troca no mercado constituíam o único domínio peculiar da economia, não havia análise econômica da família e do trabalho doméstico. Contudo, nos anos de 1960, o ingresso de mulheres (brancas e casadas) no mercado de trabalho americano provocou a necessidade de se desenvolverem programas de pesquisa para explicar a participação no mercado de trabalho de um trabalhador não masculino.

Nesse contexto surgem as primeiras aproximações de gênero no discurso econômico ortodoxo por meio dos trabalhos sobre a "nova economia doméstica" de Gary Becker (1981). O trabalho de Becker sofreu forte influência das contribuições de Reid (1934), entretanto, não existe este reconhecimento por parte dos economistas, o que é uma clara demonstração de sexismo e preconceito.

O trabalho de Becker utiliza a teoria microeconômica padrão para criar um modelo de comportamento das famílias. O modelo incorpora as 
hipóteses sobre os agentes que atuam de acordo com uma função utilitária, a de "patriarca benevolente", que assegura o consenso por meio do poder monetário (Grapard, 1999:550). Essa racionalidade econômica foi amplamente criticada por economistas feministas devido a suas hipóteses simplistas e sua complacência com o status quo (Folbre; Hartmann, 1988; Bergmann, 1995).

Com ênfase na livre escolha, o modelo ignora as restrições estruturais que limitam, desproporcionalmente, as decisões das mulheres em casa e no mercado de trabalho. E, ao analisar a família como parte de um modelo de comércio básico, com alguns preços sendo calculados em termos de combinação tempo-dinheiro, sustenta suas hipóteses com base nas vantagens comparativas que representam a produção de mercado versus não mercado.

De uma forma tautológica, explica o pagamento e o status mais baixo das mulheres no local de trabalho por meio de suas obrigações no lar, enquanto, simultaneamente, considera a desproporcional divisão do trabalho doméstico das mulheres como sendo resultado de seu pagamento mais baixo e, por conseguinte, menor custo de oportunidade no mercado de trabalho.

Entretanto, entre os vários enfoques envolvendo o tema do trabalho e especialmente o trabalho não remunerado ganharam espaço, do ponto de vista metodológico, as abordagens sobre a medição e valorização do trabalho não remunerado (Himmelweit, 1995). Neste sentido, dois enfoques se destacam: o que propõe a sua valorização dentro de uma perspectiva de compartilhamento entre os membros da família e o enfoque que defende a sua inclusão nas estatísticas que medem as contas nacionais atribuindo um valor que, além de ser medido monetariamente, seja contabilizado no Produto Interno Bruto 9 . A crítica a essa abordagem reside em uma compreensão que não será transformando o trabalho

\footnotetext{
${ }^{9}$ A exemplo de Stiglitz, Sen e Fitoussi (2009), em The measurement of economic performance and social progress revisited, vários estudos e pesquisas estão sendo desenvolvidos com o objetivo de identificar os limites do PIB como um indicador de desenvolvimento econômico e social e a importância de informações adicionais para a produção de indicadores mais relevantes para o bem-estar social.
} 
doméstico em uma mercadoria que pode ser livremente transacionada que eliminaremos a enorme carga de trabalho doméstico que recai sobre as mulheres. Dar visibilidade a esse trabalho é fundamental, mas com o propósito de denunciar a divisão sexual do trabalho e alterar essa relação.

Com a crescente participação das mulheres na força de trabalho, tornou-se óbvio que havia três situações de escolha conflitantes: entre o trabalho (de mercado) remunerado, o trabalho doméstico não pago e o lazer ${ }^{10}$. Essa nova categorização é necessária para destacar fatores que são importantes para explicar as escolhas das pessoas, especialmente as das mulheres.

Sem um entendimento teórico adequado e uma boa estimativa do valor de tempo gasto em trabalho não remunerado, os elaboradores de políticas estão propensos a subestimar o valor do tempo das mulheres e proporcionar somas subestimadas de assistência pública para os cuidados dos dependentes, por exemplo.

As questões de como quantificar o valor do trabalho desempenhado fora do mercado e de como incorporá-lo à estrutura macroeconômica são complexas. Entre as economistas feministas não há concordância a respeito da incorporação do trabalho não remunerado no cálculo do PIB (Produto Interno Bruto) como trabalho produtivo e tampouco em relação à remuneração do trabalho doméstico.

Para algumas, essa medida apenas reforçaria a percepção de que o trabalho doméstico e de cuidados são trabalhos de mulheres. Outras argumentam que, à medida que se define uma medida de magnitude e de valor do trabalho produtivo não computado, haverá consequências para a política social econômica e para as normas e instituições sociais (Benería, 1992).

$\mathrm{Na}$ análise empírica sobre a família e a participação na força de trabalho, a investigação feminista se torna mais difícil, à medida que as contas nacionais apenas medem a produção de mercado. Não há a coleta de informações sobre trabalho não remunerado exercido dentro das casas, bem como os levantamentos em relação à força de trabalho refletem

${ }^{10}$ Contudo, alguns economistas ainda descrevem a participação no mercado de trabalho a partir de escolhas conflitantes entre o mercado de trabalho e o lazer.

Temáticas, Campinas, 26, (52): 135-166, ago./dez. 2018 
noções do típico trabalhador masculino, contudo, avanços estão sendo realizados para medição dos afazeres domésticos no interior das casas.

Inicialmente, o programa de pesquisa da economia feminista foi, necessariamente, focado na identificação e análise dos preconceitos de gênero nos modelos econômicos tradicionais de análise empírica. Os métodos estatísticos padrão utilizados por economistas neoclássicos baseiam-se em extensos grupos de dados, frequentemente coletados por agências governamentais. A informação contida, por sua vez, é imperfeita e revela desde respostas impessoais até questões ambíguas. Somando-se às críticas formuladas por outros a respeito do abuso de estatísticas e à econometria (McCloskey, 1998; Nelson, 1996), as economistas feministas se opõem à exclusiva confiança em métodos quantitativos.

Portanto, em contraste à prática convencional de confiar em amplos conjuntos de dados, as aplicações feministas de métodos de pesquisa quantitativa e qualitativa tendem a valorizar mais os depoimentos por meio de entrevistas, levantamentos detalhados, pesquisa de profundidade conduzida por pesquisadores, pesquisa observador-participante e o uso de grupo focal como parte das estratégias inovadoras em andamento.

Embora as economistas feministas não compartilhem, necessariamente, uma mesma perspectiva política e ideológica, elas têm um comprometimento com as metodologias que ajudam a formular modelos teóricos e propostas práticas que contribuem para a emancipação das mulheres.

As respostas e alternativas que as economistas feministas formulam em contraposição ao modelo predominante são muito diversas. Entretanto, é possível distinguir dois tipos de trabalho econômico feminista: a economia de gênero e a economia feminista.

Como já identificamos anteriormente, não há uma homogeneidade da crítica à economia predominante feita pelas economistas feministas. Se, por um lado, se reconhece o caráter autoritário e neutro dessa economia; por outro lado, existe um entendimento entre algumas economistas que se consideram feministas, ou que trabalham com o tema de gênero ou família, de que é possível melhorar a economia neoclássica revogando preconceitos masculinos e, desta forma, aumentando a eficiência da 
economia. Refutam os pontos de vista que defendem a necessidade de se construir uma alternativa econômica feminista.

\title{
4. AS ABORDAGENS NO CAMPO DA ECONOMIA FEMINISTA: CONCILIAÇÃO E RUPTURA
}

No campo da economia feminista podemos identificar duas abordagens: de conciliação e de ruptura. A economia feminista se propõe a uma revisão da epistemologia predominante nas ciências econômicas ao questionar a divisão sujeito/objeto, a identidade do sujeito que produz conhecimento e que é tratado como um ser abstrato, dotado de razão e acima dos interesses de gênero, e o critério da objetividade como legitimador do conhecimento. Para a economia feminista, a objetividade não é neutra, pelo contrário, ela oculta os verdadeiros interesses que formam a base do discurso científico (Orozco, 2005:49).

\begin{abstract}
A nivel del ámbito de estudio, la economía feminista se caracteriza por asumir como tarea prioritaria el replanteamiento de la estructura androcéntrica que identifica la economía con lo monetizado y desvelar los sesgos androcéntricos subyacentes. En primer lugar, se pretende dar una definición más amplia de lo económico que, de forma clave, atienda a las actividades invisibilizadas históricamente realizadas por las mujeres. Se trata, por tanto, de descentrar a los mercados hacia los que se habia dirigido la mirada primordial o exclusiva. Este descentramiento tiene que permitir, en segundo lugar, una recuperación de los elementos femeninos invisibilizados, recuperando a las mujeres como agentes económicos. En tercer lugar, es necesario mostrar las relaciones de poder de género que subyacian a la estructura dicotómica y, a la par, convertir dichas relaciones en un objeto legítimo de estudio económico. (Orozco, 2005:50)
\end{abstract}

Tudo isso tem consequências metodológicas que implicam reformulações profundas dos marcos preexistentes. Portanto, a economia feminista se apoia em um enfoque normativo e assume como tarefa a busca de soluções. 


\subsection{A ECONOMIA FEMINISTA DE CONCILIAÇÃO}

A economia feminista de conciliação busca redefinir os princípios da economia e do trabalho, recuperando o conjunto de atividades femininas que se tornaram invisíveis pela teoria econômica. Essa tarefa envolverá diferentes momentos.

Em primeiro lugar, trata-se de tornar visível o trabalho doméstico e de reprodução, redefinir o conceito de trabalho para contemplar o trabalho doméstico e a medição desse trabalho por meio de sistemas de contabilidade nacional, bem como desenvolver o método mais adequado para a medição.

Em segundo lugar trata-se de tornar visível a desigualdade nas relações de gênero. Para que se possa compreender essas implicações de gênero, é fundamental integrar na análise econômica termos até então fora deste campo de análise, como, por exemplo, gênero, sexo e patriarcado.

Como desdobramentos, aparecem dois conceitos centrais: a divisão sexual do trabalho e o conceito de família nuclear tradicional. A divisão sexual do trabalho, de origem marxista, mas que posteriormente seria utilizada pelo conjunto de economistas feministas de conciliação, pretende captar toda uma estrutura social em que mulheres e homens têm condições diferentes no trabalho profissional e doméstico (Maruani, 2000:65). O conceito de família nuclear tradicional, baseado no modelo de homem provedor e mulher dona de casa, tem sua origem vinculada às análises micro de recorte neoclássico

Em terceiro lugar, se analisa as causas da desigual divisão entre mercado e não mercado, e, para essa questão, se colocam duas explicações. A primeira se concentra no economicismo e numa visão unidirecional, atribuindo tudo que ocorre no âmbito doméstico como consequência de interesses e processos oriundos do mercado. Para os que compartilham dessa abordagem, é a preponderância de uma lógica do capital que determina o que ocorre no âmbito doméstico. A decorrência dessa explicação, para uns, será a aplicação de um método marxista, sem, no entanto, reelaborá-lo; para outros, a aderência à metodologia neoclássica, pois consideram que é a lógica de maximização da função utilidade que explica os processos mercantis e não mercantis. 
A segunda explicação reconhece que a realidade é uma complexa interação de forças mercantis e não mercantis, de relações de classes e de gênero que estão entrelaçadas e agem de forma simultânea.

Essas duas explicações podem ser consideradas bidirecionais, que atendem a elementos até então ausentes das análises econômicas, o que torna necessária, com a introdução de novos conceitos, a ampliação das categorias econômicas.

Para Orozco, essa abordagem é a que mais tem evoluído nos estudos da economia feminista, uma vez que reconhece que existe um processo de realimentação das condições de desigualdade entre mulheres e homens presente no âmbito doméstico e do mercado (Orozco, 2005:53).

Enfim, é a partir da análise de ambas as esferas econômicas que se poderá explicar a totalidade da realidade e da atividade econômica das mulheres. O enfoque da produção - reprodução, proposto por Carrasco (2006), é o que mais claramente mostra que, ao integrar essas duas esferas econômicas atribuindo-lhes a mesma importância analítica, pretende-se entender os processos de geração de bem-estar social (Carrasco, 2006).

\subsection{A ECONOMIA FEMINISTA DE RUPTURA}

O centro de análise da economia feminista de ruptura situa-se na sustentabilidade humana. Para essa abordagem, não é suficiente integrar uma nova esfera de atividade econômica como a casa, o trabalho doméstico e a reprodução, conforme propostas da análise da economia feminista de conciliação, uma vez que as análises continuarão a privilegiar o que ocorre no mercado, e as esferas consideradas não econômicas continuarão sendo analisadas de forma derivada e, portanto, secundarizadas (Himmelweit, 1995).

Segundo Orozco, produção e reprodução não têm o mesmo valor analítico, uma vez que, a produção e os mercados não possuem valor em si mesmos, mas à medida que colaboram ou impedem a manutenção da vida, que é a categoria central de análise.

A adoção do conceito de sustentabilidade da vida como categoria primária de análise não significa uma definição fechada e estática da 
economia, mas a procura de abrir um espaço ao conjunto de relações sociais que garantem a satisfação das necessidades das pessoas e que estão permanentemente em transformação (Power, 2004). Esse enfoque renuncia à busca de um sujeito unitário com uma experiência e interesses comuns que definem a mulher no mundo, reconhece a diferença e as relações de poder que se estabelecem entre as próprias mulheres.

Para Carrasco, as necessidades humanas não se resumem aos bens e serviços, mas também aos afetos e às relações (2001:14). Isso significa que os valores tradicionalmente associados às mulheres como o cuidado, e que sempre estiveram na periferia das análises econômicas, devem ser revalorizados e reconhecidos. Desse ponto de vista, a noção de trabalho utilizada para delimitar o trabalho realizado no mercado necessita ser ampliada para incorporar todas as atividades que entram na formação de parte do processo de sustentabilidade da vida humana.

Portanto, identifica-se na formulação que propõe medidas de igualdade de oportunidades uma aproximação da economia de gênero, em que se reforçam os parâmetros definidos a partir do masculino e do mercado como o ideal a ser alcançado. Entre as feministas adeptas das políticas de conciliação entre trabalho e família, encontramos a segunda definição, cujas políticas de conciliação podem ser identificadas, nos países desenvolvidos, por meio das políticas de trabalho em tempo parcial; e, nos países em desenvolvimento, pela utilização do emprego doméstico. Em ambas as teorias, a resolução entre casa e trabalho é responsabilidade das mulheres. A primeira não propõe soluções para o trabalho doméstico, reforçando a dupla jornada, e, na segunda, as soluções aprofundam a precarização do trabalho. Sendo assim, somente modificando-se a lógica mercantil que domina o sistema econômico, como sugerido pela economia feminista de ruptura, é que se terá formas alternativas de se ver o mundo.

A proposta da economia feminista é repensar o pensamento econômico com o objetivo de melhorar as condições econômicas das mulheres, a teoria econômica e as políticas em que ela está fundamentada. O principal argumento que sustenta esse objetivo é que a maior parte das bases e recomendações de políticas econômicas está fora de lugar e de tempo, tais políticas são produto de uma determinada época em que foram 
concebidas e desenvolvidas, e do sexismo presente em nossas sociedades. A economia é considerada como algo distante das lutas sociais e políticas e, especialmente, do movimento feminista.

Supõe-se que a economia seja uma ciência objetiva e que seus modelos e metodologias foram desenhados para assegurar uma análise rigorosa e precisa. Para a economia feminista, a economia tradicional está longe de ser objetiva e neutra. A definição de economia como uma ciência que está baseada em modelos matemáticos e nas escolhas racionais dos indivíduos assume pontos de vista sobre a identidade humana e sobre a natureza do conhecimento que estão ligados ao androcentrismo tradicional. Tal definição reforça o individualismo com a figura do "homo economicus", sujeito autônomo, racional e livre para escolher entre distintas possibilidades.

A teoria feminista argumenta que certos modelos, temas e metodologias da teoria econômica foram resultados de um processo altamente influenciado pelas percepções dos economistas sobre o valor de atividades e atributos que eram vistos como masculinos ou femininos. É possível identificar, entre os economistas tradicionais, a preferência por enfoques de áreas mais "formais", como comércio e governo, e certa secundarização das áreas relacionadas com a equidade social e econômica (Ulloa, 2000).

As contribuições da economia feminista para a teoria econômica, assim como para outras disciplinas, têm quatro componentes fundamentais: i) dar visibilidade às mulheres como sujeitos, legitimando suas experiências e perspectivas; ii) reconhecer e entender as desigualdades entre mulheres e homens; iii) modificar a teoria, a metodologia e as práticas da disciplina econômica; e iv) desenvolver um método que inclua todas as pessoas.

Nesse sentido, a economia feminista, com foco na sustentabilidade da vida humana, se constitui em um instrumento valioso de análise que permite uma crítica global ao sistema capitalista e à economia de mercado e, por isso, foi mais rapidamente incorporada pelos movimentos feministas que questionam o liberalismo econômico e a globalização. A sua influência pode ser constatada nas ações da Marcha Mundial das Mulheres no Brasil e em organizações feministas como a SempreViva Organização 
Feminista - SOF que vêm desenvolvendo suas estratégias a partir de uma perspectiva que coloca no centro a vida humana em contraposição ao mercado, valorizando o trabalho reprodutivo realizado pelas mulheres e denunciando o paradigma dominante que desconsidera as desigualdades entre os sexos como consequência da divisão sexual do trabalho. A partir dessa perspectiva várias iniciativas importantes merecem destaque, a exemplo do enfoque da economia solidária, do trabalho no campo e a presença significativa das mulheres na agricultura familiar, o significado do enorme contingente de mulheres envolvidas com o trabalho doméstico no Brasil e número relevante de mulheres que se encontram em atividades não remuneradas ou simplesmente fora da força de trabalho.

\section{CONSIDERAÇÕES FINAIS}

Vimos que o pressuposto do comportamento racional desempenha um papel fundamental na economia moderna. Supõe-se que as pessoas se comportem de um modo racional que não difere da descrição do comportamento real. $\mathrm{Na}$ teoria econômica predominante existem dois métodos que definem a racionalidade do comportamento. Um considera a racionalidade como a consistência interna nas escolhas e outro identifica a racionalidade com a maximização de seus próprios interesses. Com isso a natureza da economia moderna foi profundamente comprometida pelo distanciamento crescente entre o mundo real, em especial pelo abandono das considerações relacionadas à motivação humana e aquelas do âmbito social. Por outro lado, afastou totalmente a possibilidade de inclusão do processo de reprodução social da estrutura analítica geral da economia política com a substituição da teoria valor trabalho por um modelo de valor utilidade, dessa forma, deslocando o valor da esfera da reprodução para um conceito de preço de equilíbrio definido no âmbito do mercado.

Além disso, o paradigma dominante não reconhece a existência de relações de poder sociais e econômicas entre classes, raças e sexos. Ao reduzir a teoria às escolhas individuais tem implicações particularmente significativas na formulação de um padrão teórico para explicar as relações humanas no interior das relações familiares e nas relações com a sociedade 
e, ao não distinguir as diversidades existentes, reduz os indivíduos ao modelo de um homem branco. Nas relações no interior das famílias busca enquadrar a teoria ao conceito da nova economia doméstica, que trata as decisões das mulheres em participar ou não do mercado de trabalho como simples escolhas maximizadoras de resultados, desprezando as relações sociais de sexo que se configuram no interior das famílias e da sociedade pela interação entre produção econômica e reprodução social determinante na sustentação desse sistema econômico e social.

Portanto, esses modelos que se formam no interior da teoria não são capazes de explicar a posição inferior das mulheres em várias sociedades, quais as justificativas para que a metade da humanidade siga sendo tão discriminada por meio de salários menores e segregadas em ocupações carregadas de estereótipos?

A partir do questionamento a estes pressupostos as economistas feministas desenvolveram uma crítica aos métodos da economia predominante. Um grande número de economistas defende o pensamento econômico em um padrão que seja mais permeável às necessidades e bem-estar das mulheres e, com isso, buscaram desafiar as resistências disciplinares ao pensamento feminista. Suas contribuições também avançaram no sentido de alterar as formas institucionais que marginalizaram o pensamento econômico feminista desde os seus primórdios, dando visibilidade as pesquisas e investigações que enfatizavam as diferenças entre os sexos em distintas abordagens até então negligenciadas pela disciplina econômica.

As mulheres estavam subsumidas nos cálculos e nas projeções que adotam um comportamento universal para explicar as dinâmicas sociais e econômicas. É, principalmente, na economia do trabalho que os resultados são mais promissores. A segregação ocupacional, a discriminação de gênero e as disparidades salariais estão entre as muitas áreas em que as economistas mulheres contribuíram para reduzir os preconceitos de gênero na teoria econômica e revelar as imbricações de sexo, classe e raça como constituinte de uma sociedade profundamente desigual, a partir dos aportes da sociologia do trabalho. Uma outra contribuição fundamental está relacionada a inclusão do trabalho doméstico não remunerado nos 
modelos econômicos e nas medidas de políticas públicas.

O foco da teoria macroeconômica é manter estáveis os níveis de preço, crescimento do produto constante e pleno emprego. A partir das contribuições da economia feminista novas elaborações estão sendo propostas no sentido de revisar as teorias e políticas macroeconômicas que se concentram na análise do comportamento do produto como a principal medida de eficiência de uma economia e ampliar o seu foco para outros aspectos da vida econômica.

Embora as pesquisas ainda sejam muito incipientes, mas existe todo um esforço em expandir para outras formas de atividades produtivas realizadas, principalmente, no âmbito das famílias, nos cálculos do produto e, com isso, aproximar a economia monetária que é realizada no mercado, da economia humana realizada no âmbito doméstico.

Para nosso objeto de análise é essencial compreender as interações que se constituem entre os sistemas econômicos e de reprodução social na manutenção da discriminação e exclusão das mulheres do mundo produtivo em um sistema - uma vez que as políticas de ajuste estrutural de cunho neoliberal vem reduzindo de forma continua as políticas públicas dos Estados - que necessita cada vez mais do enorme volume de trabalho gratuito realizado pelas mulheres no âmbito do trabalho doméstico que envolve cuidados, afeto, bem estar e suporte emocional. Por outro lado, é essencial reconhecer que as desigualdades de gênero e raça são estruturantes de uma sociedade de classes.

\section{REFERÊNCIAS BIBLIOGRÁFICAS}

BECKER, Gary. Tratado sobre la familia. Madrid: Alianza Editorial, 1987.

BENERÍA, Lourdes. Accounting for women's work: the progress of two decades, world development. Science Direct, vol. 20 (11), 1992.

BENERIA, Lourdes. Introducción. La mujer y el género sem la economia: sem panorama general. Gender, Development and Globalization. Copyright, 2004. 
BERGMANN, Barbara. The task of a feminist economics: a more equitable future. In: FARNHAM, Christie (ed.). The impact of feminist research in the academy. Bloomington: Indiana University Press, 1987.

BERGMANN, Barbara. Becker's theory of the family: preposterous conclusions. Journal feminist economics. Volume 1. 1995. P. 141-50.

CARRASCO, Cristina. La economia feminista: Sem apuesta por sem economia. In: VARA, Maria Jesús (coord.). Estudios sobre género y Economia, Madrid: Ed. Akal, 2006.

. La sostenibilidad de la vida humana: ¿semEconomia de mujeres? Barcelona: Revista Mientras Tanto, n. 82. Icaria Editoral, 2001.

FERBER, Marianne \& NELSON, Julie. Beyond Economic Man: A feminist theory and Economics. Chicago: University of Chicago Press,1993..

FOLBRE, Nancy \& HARTMANN, Heidi. The rhetoric of self-interest: ideology and gender in economic theory. In: KLAMER Arjo, McCLOSKEY, Donald N. and SOLOW, Robert (eds). The consequences of economic rhetoric. New York: Cambridge University Press, 1988. P.184-203.

FRIEDAN, Betty. Mística feminina. Rio de Janeiro: Vozes, 1971.

GODINHO DELGADO, Maria do Carmo. Estrutura de governo e ação politica feminista: a experiência do PT na prefeitura de São Paulo. São Paulo: PUC. Tese de doutorado. 2007

GRAPARD, Ulla. Methodology. In: PETERSON, Janice and LEWIS, Margaret (eds), The Elgar Companion to Feminist Economics. Cheltenham, UK; Northampton, MA: Edward Elgar Publishing, 1999.

HARDING, Sandra. The science question in feminism. Ithaca, New York: Cornell University Press, 1986.

HARDING, Sandra. Whose science? Whose Knowledge? Thinking from women's lives. Ithaca, New York: Cornell University Press,1991. 
HIMMELWEIT. S, \& MOHUN, S. Domestic Labor and Capital. Cambridge Journal of Economics 1, March: 1-19. 1975.

HIRATA, Helena. Nova divisão sexual do trabalho? Um olhar voltado para a empresa e a sociedade. São Paulo: Boitempo, 2002.

KERGOAT, Danièle. Divisão Sexual do trabalho e relações sociais de sexo. In: HIRATA, Helena; LABORIE, Françoise; LE DOARÉ, Hélène (org). Dicionário Crítico do Feminismo. São Paulo: Editora UNESP, 2009. P. 67-80.

MADDEN, Janice F. The Development of Economic Thought on the "Woman Problem". Review of Radical Political Economics, 4 (3): 21-38, 1972.

MARUANI, Margareth. Travail et emploi des femmes. Paris. La Découvert, 2000. P.55-69.

McCLOSKEY, Deirdre. The rhetoric of economics. The university of economia press. Second ed. 248 p. 1998.

MacDONALD, Martha. Economism and feminism. The dismal science. Studies in political economy, 15 (fall): 151-78. 1984.

McFARLAND, Joan. A critique of the scope of traditional analysis and research. Atlantis, 1, (2): 26-41, 1976.

MCKINSEY \& Company. A future that works automation, employment, and productivity. January 2017.

MINCER, Jacob. Labor force participation of married women: a study of labor supply. In: Aspects of labor economics. NBCR. Princeton University Press, 1962.

NELSON, Julie. A. Feminism, objectivity and economics. London and New York: Routledge,1996.

NUSSBAUM, Martha. Las mujeres y el desarrollo humano. El enfoque de las capacidades. Barcelona: Editora Herder, Universidad Cambridge, 2000. 
OROZCO Pérez, Amaia O. Economía del género y economia feminista. ¿Conciliación o ruptura?. Revista Venezolana de Estudios de la Mujer. Caracas. Enero-Junio 2005, Vol.10, n. 24.

POWER, Marilyn. Social Provisioning as a Starting Point for Feminist Economics.Feminist Economics, vol. 10 No 3, pp. 3-19. 2004.

PICCHIO, Antonella. Visibilidad analítica y política del trabajo de reproducción social. In: CARRASCO, Cristina (ed.) Mujeres y economia. Nuevas perspectivas para viejos e nuevos problemas. Barcelona: Icaria, 1999. P. 201-42.

REID, M. Economics of household production. New York: John Wiley, 1934.

ROBEYNS, Ingrid. Há uma metodologia econômica feminista? $3^{a}$ versão, 14/10/2000. Faculdade Wolfson. Cambridge. Reino Unido. Versão em português.

SEM, Amartya. Sobre ética y economia. Vérsion de Ángeles Conde. El livro Universitário Alianza Editorial,1999.

ULLOA, Maria. Mesa de trabajo. Teoría y economias de la economia feminista. In: Mujeres y Economia Colombia. Agosto, 2000.

VANDELAC, Louise. L'économic des femmes?', Cabiers de recherche sociologique, 4. (1): 15-32. 1986.

Submetido em: 11/10/2018 e aceito em 13/10/2018. 